\title{
The role of autophagy in bacterial infections
}

\author{
Nayeli Shantal Castrejón-Jiménez ${ }^{1}$, Kahiry Leyva-Paredes ${ }^{1}$, Juan Carlos Hernández-González ${ }^{2}$, \\ Julieta Luna-Herrera ${ }^{1}$, Blanca Estela García-Pérez ${ }^{1, *}$ \\ ${ }^{1}$ Departamento de Inmunología, Escuela Nacional de Ciencias Biológicas, Instituto Politécnico Nacional, Prolongación de \\ Carpio y Plan de Ayala S/N, México, México; \\ ${ }^{2}$ Área Académica de Medicina Veterinaria y Zootecnia, Instituto de Ciencias Agropecuarias-UAEH. Av Universidad km. 1. Ex- \\ hacienda de Aquetzalpa A.P. 32, Tulancingo, Hgo. México.
}

\begin{abstract}
Summary Autophagy is a highly conserved catabolic process for the degradation of cytosolic components including damaged organelles, protein aggregates, and intracellular bacteria through a lysosome-dependent pathway. Autophagy can be induced in response to stress conditions. Furthermore, autophagy has been described as involved in both innate and adaptive immune responses, and several studies have shown that certain microorganisms can be eliminated by the autophagic route in a process known as xenophagy. However, several pathogens have developed different strategies to evade or exploit autophagy to ensure their survival. Here, we review the role of autophagy in response to bacterial pathogens.
\end{abstract}

Keywords: Autophagy, xenophagy, selective autophagy, pathogens

\section{Introduction}

The catabolic pathway of autophagy is essential for homeostasis, acting as a mechanism for cell survival during stress and maintaining cellular integrity by regenerating metabolic precursors and removing subcellular components (1-3). In the cell, the autophagic pathway has several functions including selective degradation of intracellular pathogens, removal of damaged organelles or excess thereof, and elimination of potentially toxic protein aggregates. The pathway is also involved in the degradation of proteins and other macromolecules to deliver essential anabolic nutrients under conditions of nutritional stress or inanition. Autophagy is closely related to maintaining the health of the organism and that its malfunction or absence contributes to the development of certain diseases like cancer, Huntington's disease, Parkinson's disease, and cardiomyopathy-related myodegeneration (4). Several studies have linked autophagy with the innate and adaptive immune responses, including roles

\footnotetext{
*Address correspondence to:

Dr. Blanca Estela García Pérez. ENCB, Instituto Politécnico Nacional. Prolongación de Carpio y Plan de Ayala S/N, 11340, México City, México.

E-mail: abrilestela@hotmail.com
}

in regulatory and effector functions, tolerance and inflammation. The peptides produced by autophagic degradation can be presented to $\mathrm{T}$ cells through major histocompatibility complex class I (MHC I) and MHC II molecules (5). Furthermore, autophagy is an effector in Th1/Th2 polarization (6-8). In innate immunity, autophagy is the effector response of activation receptors such as Toll-like receptors (TLRs) and NOD-like receptors (NLRs) in response to pathogens and damage-associated molecular pattern molecules (DAMPs) (9-14).

Initially, autophagy was considered to be a nonselective process. However, it has been shown that this process can selectively remove protein aggregates (aggrephagy); organelles such as peroxisomes (pexophagy), mitochondria (mitophagy), endoplasmic reticulum (reticulophagy), and ribosomes (ribophagy); lipids (lipophagy); and bacteria and viruses (xenophagy) (4,15-20). Selective autophagy can act as a qualitycontrol mechanism in the cell, ensuring the degradation of cytoplasmic components or microorganisms that escape canonical autophagy $(21,22)$.

The autophagy is in some cases an efficient pathway to degradation of microorganisms but, several pathogens have taken advantage the autophagy machinery to survive and replicate. Here, we will review these dual functions of autophagy in the bacterial infections. 


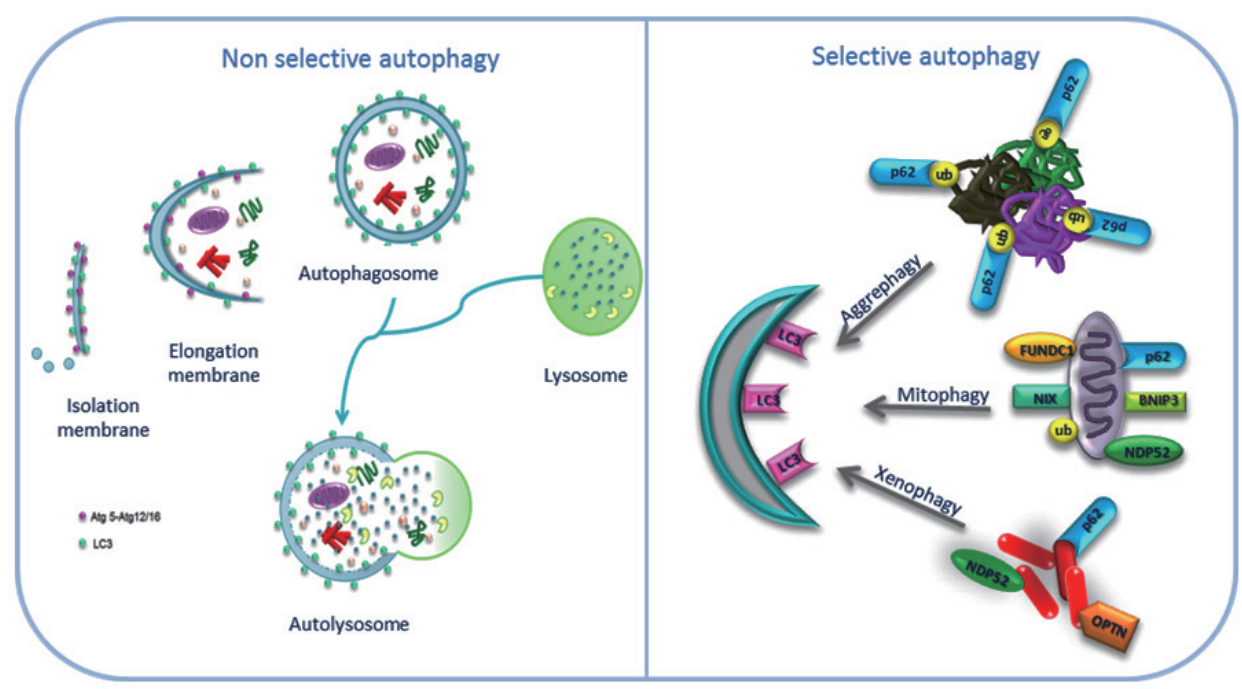

Figure 1. Schematic representation of autophagy. Non selective autophagy is a bulk degradation system that involves the isolation and elongation membrane to form a specialized double-membrane vesicle called the autophagosome. The autophagosome envelops target cytosolic materials and fuses with lysosome to give rise to a structure of enzymatic degradation known as autolysosome. Selective autophagy is a process that involves the specific degradation of targets as aggregated proteins, mitochondria and pathogens. The ubiquitination of substrates and the cargo adaptor proteins play an important role in selective autophagy.

\section{Nonselective autophagy}

The main feature of autophagy is the formation of membranous organelles called autophagosomes (Figure 1). The formation of these structures is controlled by proteins encoded by autophagy-related genes (ATGs). In total, 37 ATG proteins have been described in yeast, of which ATG 1-10, ATG 12-14, ATG 16-18, and ATG 17, 29, and 31 are essential in the formation of autophagosomes (23). These proteins are hierarchically organized into functional complexes that regulate several steps of the autophagic process. The formation of autophagosomes can be divided into three stages: initiation, nucleation and elongation (2). At the transcriptional level, the regulation of autophagy is coupled to the lysosomal pathway by transcription factor EB (TFEB) (24) and to other proteolytic systems via FOXO3a (25). However, autophagy is activated through fast signaling pathways in response to stress conditions and membrane remodeling in the cytoplasm and these signals occur more rapidly than the transcriptional changes in the nucleus do (26). The molecular machinery used in autophagosome formation can be divided into four groups: $i$ ) the UNC51-like kinase (ULK) complex, which includes UNC51like Ser/Thr kinases ULK1 and ULK2, ATG 13, FAK family kinase-interacting protein of $200 \mathrm{kDa}$ (FIP200) and ATG101 which is activated by mTORC1; ii) the complex formed by the phosphatidylinositol 3-kinase class III (PI3K) Vps34 and BECN1, which labels the site of autophagosome generation by increasing the local concentration of phosphatidylinositol 3-phosphate; iii) the transmembrane proteins ATG9 and VMP1, which are involved in recruiting membrane for autophagosome formation; and $i v$ ) two systems of ubiquitin conjugation, or ATG12-like and MAP1LC3 (also known as LC3, GABARAP and GATE-16).

\section{Selective autophagy}

Approximately $1-1.5 \%$ of cellular proteins are catabolized by autophagy every hour. Under homeostatic conditions, the proportion of basal autophagy that contributes to synthesis and energy production is not clear. However, it is known that basal autophagy acts as a quality-control mechanism for cytoplasmic components and is crucial in several postmitotic cells, such as neurons and hepatocytes. Although this quality control is partly achieved by nonselective autophagy, increasing evidence suggests that under special conditions, autophagy can selectively degrade aberrant proteins, lipids, dysfunctional organelles, and microorganisms (Figure 1). Selective autophagy can occur constitutively and can also be induced in response to cellular stress (2). This type of autophagy can be classified according to the substrate degraded: protein aggregates (aggrephagy) $(27,28)$; peroxisomes (pexophagy) $(19,29)$; mitochondria (mitophagy) (18,30); glycogen (glycophagy) (31); endoplasmic reticulum (reticulophagy) (15); zymogen granules (zymophagy) (32); lipids (lipophagy) (20); ribosomes (ribophagy) (33); and bacteria, viruses and protozoa (xenophagy) (34).

Selective autophagy is based on the recognition of specific substrates for degradation. This process is dependent on receptors that bind to LC 3 through a small motif called an LC3-interacting region (LIR). The motif LIR is a degenerate sequence of amino acids with a core corresponding to $\mathrm{W} / \mathrm{F} / \mathrm{Y}-\mathrm{XX}-\mathrm{L} / \mathrm{I} / \mathrm{V}$ (where $\mathrm{X}$ can be any amino acid) (35). The receptors involved in selective autophagy recognize ubiquitinated substrates, 


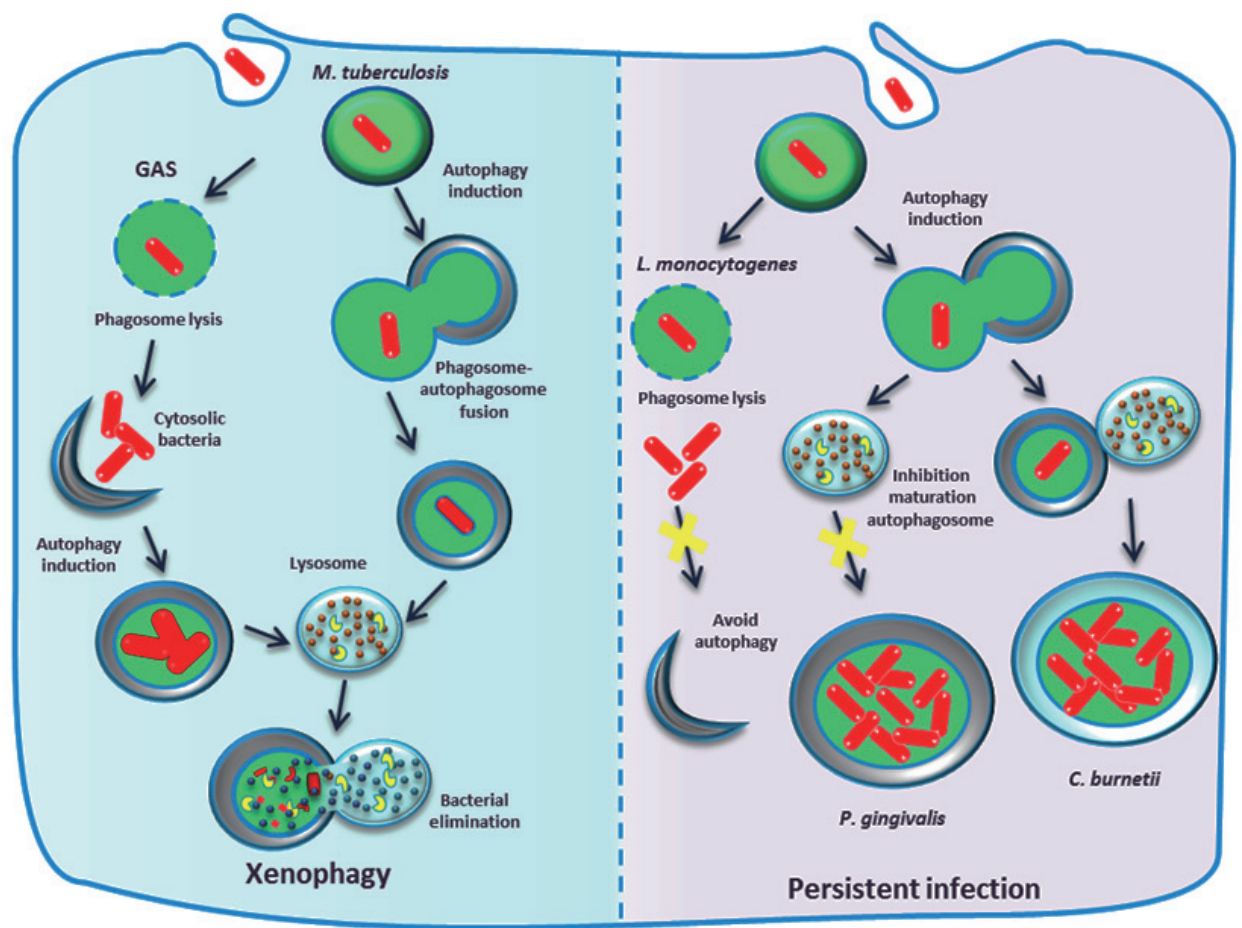

Figure 2. The role of autophagy in bacterial infections. (A) In some bacterial infections autophagy plays a role as a defense mechanism. Some bacteria (for example S. pyogenes, GAS) induce the selective autophagy when disrupt membrane of the endocytic vacuole and escape to cytosol. Another bacterium, like M. tuberculosis, is sequestered in autophagosome and the autophagosome maduration and fusion with lysosome are allowed. In both cases, pathogens are eliminated in autolysosome by enzymatic degradation (Xenophagy). (B) In contrast, L. monocytogenes avoid autophagy and survives into cell. P. gingivalis and C. burnetti, use the autophagy pathway to generate a replicative niche in which they can survive and replicate actively. These pathogens take advantage of the host intracellular trafficking pathway and autophagy.

and this recognition is mediated by adaptor molecules that are attached to ubiquitin at one end and to other members of the LC3 family (LC3/GABARAP/GATE16) on the other end (36) (Figure 2). The first receptor involved in selective autophagy to be identified was p62 (also known as sequestosome-1 (SQSTM1)) $(27,28,37)$. It is well known that p62 is a scaffold protein that has an important role in signaling pathways involving NF-kB (38). However, p62 colocalizes with protein inclusions in diseases such Alzheimer's disease, Pick's disease, Lewy body dementia, and Parkinson's disease $(39,40)$. Studies with autophagy-knockout mice have shown that $\mathrm{p} 62$ plays an important role in regulating the formation of protein aggregates, and the binding of this receptor allows LC3 protein degradation by the autophagic pathway (37). These studies showed that if autophagy is blocked, p62 cannot be degraded, leading to excessive accumulation of aggregated proteins and severe hepatomegaly and liver dysfunction (37). After the discovery of p62, it was demonstrated that nuclear dot protein, $52 \mathrm{kDa}$ (NDP52) is another receptor involved in the autophagic process. Studies by Thurston and colleagues in 2009 showed that NDP52 is a receptor involved in autophagy that, similar to $\mathrm{p} 62$, binds to ubiquitinated S. typhimurium. In this same study, it was shown that the binding of ubiquitin to NDP52 depends on the receptor's zinc fingers' detection of polyubiquitinated bacteria. Cells infected with S. typhimurium and lacking NDP52 showed an accumulation of ubiquitinated bacteria in the cytosol, thus demonstrating the importance of this receptor in xenophagy (41).

A receptor that was recently described as a selective autophagy receptor is optineurin (OPTN) (42). Wild and collaborators demonstrated that Salmonella enterica coated with ubiquitin is recognized by OPTN, promoting xenophagy. Moreover, they showed that the protein TBK1 phosphorylates OPTN at Serine 177, enhancing the binding affinity for LC3 and removing bacteria from the cytosol. Mutant TBK or OPTN in cells or silenced TBK or OPTN resulted in increased intracellular bacterial growth (42). Although the precise molecular mechanisms of selective autophagy have not been established, a growing number of receptors responsible for the recognition of specific substrates have been identified.

Moreover, recent studies have shown that phagosomes containing bacteria, dead cells and latex particles can recruit LC3. This is another type of selective autophagy, in which LC3 can be conjugated to phagosomes. The association of LC3 with phagocytosis (LC3-associated phagocytosis, or LAP) promotes degradation of the material containing-phagosome by induction of phagolysosomal fusion. In both LAP and autophagy, the presence of LC3 is necessary for the degradation of cargo by lysosomal enzymes. In contrast 
to canonical autophagy, defined by the formation of a double-membrane autophagosome, in LAP, LC3 is recruited directly to the phagosome (and is conjugated to phosphatidylethanolamine in this compartment) $(12,43)$. LC3 can also be conjugated directly to entotic vacuoles, macropinosomes, or phagosomes harboring apoptotic cells, and this conjugation is dependent on ATG7, ATG5, and class III Vps34 (44).

\section{Xenophagy}

The exact mechanism of bacterial recognition by autophagy has not been elucidated. However, it is known that this process requires ubiquitination (45). Autophagy receptors such as p62 (SQSTM1), neighbor of BRCA1 gene 1 (NBR1), NDP52 and OPTN are a subset of pattern recognition receptors (PRRs) called SQSTM1/p62-like receptors (SLRs). These receptors recognize ubiquitinated substrates, recruit membrane to autophagosomes and interact with LC3 (26).

The first report indicating that bacteria could be eliminated by autophagy was published three decades ago. In 1984, Rikihisa observed autophagosome formation in polymorphonuclear cells from guinea pigs infected by Rickettsia conorii (46). Before the discovery of the components of the autophagic machinery, it was difficult to unequivocally identify autophagosomes due to a lack of markers. It was also complicated to follow the dynamics and fate of intracellular bacteria, and it was difficult to determine the importance of the association of autophagosomal membranes and bacteria in host defense (4). However, with new tools available to identify autophagosomes and to block autophagy in infected cells, it has become clear that autophagy has a crucial role in the elimination of pathogens $(7,47)$.

\subsection{Streptococcus pyogenes}

The capacity to eliminate bacteria by the autophagic pathway was initially demonstrated in $S$. pyogenes, also known as Group A Streptococcus (GAS). Streptolysin O (SLO), a member of the family of cytolysins, which are pore forming and dependent on cholesterol, is a major virulence mechanism of GAS (48). SLO allows the bacteria to escape from the endosome and into the cytosol. In 2004, Nakagawa and colleagues showed that in a GAS-infected HeLa cell line, $80 \%$ of the bacteria were captured by autophagosomes and were eliminated after the fusion of the autophagosomes with lysosomes. In contrast, in GAS-infected ATG5-/- cells (deficient in autophagy), the bacteria survived and multiplied within the cells (47). It was also demonstrated that SLO was necessary for the autophagic process. Assays showed that SLO-mutant bacteria were not sequestered in autophagic structures and survived longer than the wildtype strain did. It was also shown that GAS-infected HeLa cells deficient in SLO remained in endosomes and did not escape to the cytosol, suggesting that bacterial exposure to the cytosol can function as the activation signal for autophagy. Additionally, the researchers demonstrated that the CD46 receptor induces autophagy and GAS removal by activated BECN1 and PtdIns3K (48). In addition to the ATG proteins, members of Rab GTPase family are located in autophagosomes containing GAS and are involved in autophagosome formation. For example, Rab7 mediates late endosome formation, and Rab23 regulates intracellular vesicle transport $(48,49)$. Rab9A is required for the fusion of lysosomes with autophagosomes, and this GTPase is involved in the transport of proteins from late endosomes to the trans-Golgi (50). Rab9A and Rab23 are not involved in autophagy induced by starvation (classical or canonical autophagy), suggesting that they have a unique role in xenophagy (51).

Studies in human oropharyngeal keratinocytes infected with GAS showed that GAS uses both SLO (required for association with ubiquitin) and streptolysin $\mathrm{S}$ (SLS, which is required for association with galectin $8)$ to damage the vacuolar membrane. Consequently, adapters bind ubiquitin or galectin 8 , and autophagy is induced. However, although autophagy is induced, this study showed that SLO promotes bacterial survival in human oropharyngeal keratinocytes and, together with NAD glycohydrolase (a toxin that is encoded in the same operon), inhibits the fusion of GAS containingautophagosomes with lysosomes (52). Therefore, in human oropharyngeal keratinocytes, GAS infection does not induce a xenophagic response, and bacterial toxins inhibit the formation of mature autolysosomes and allow bacterial survival. In the keratinocyte, the cell-bacterium interaction is more complex than that observed in HeLa cells, in which autophagy kills most GAS bacteria during early infection (47). GAS is a model of intracellular bacteria whose strategy to manipulate the host autophagy pathway is currently under investigation. Recently, Barnett and colleagues provide evidence about the ability of GAS to produce a protease that degrades host proteins that target bacteria to autophagy in order to evade autophagy and replicate efficiently in the cytosol of infected epithelial cells (53).

\subsection{Salmonella typhimurium}

Other studies have shown that Salmonella enterica serovar Typhimurium ( $S$. typhimurium) is also eliminated by the autophagic pathway. S. typhimurium is a facultative intracellular bacterium that usually resides in a Salmonella-containing vacuole (SCV). A unique feature of cells infected by Salmonella is the presence of tubular structures from the SCV, which are often spread throughout the cytosol of the cell. These tubules include Salmonella-induced filaments (SIFs) and sorting nexin3 (SNX3) (54,55). In this compartment, $S$. typhimurium can replicate and modify 
the fate of the SCV through its type III secretion system (T3SS, encoded in Salmonella pathogenicity islands 1 and 2 (SPI-1 and SPI-2)) and is capable of damaging the eukaryotic cell membranes. This pathogen forms a pore in the SCV via SPI-1 T3SS to escape into the cytosol, where it obtains nutrients for its growth (56). In the cytosol, S. typhimurium is coated by polyubiquitinated proteins, which are detected by the p62 adapter, after which p62 colocalizes with LC3 and LAMP1, resulting in infection control $(57,58)$. Another adapter protein that has an important role in the control of $S$. typhimurium infection is OPTN. Wild and colleagues demonstrated that activation of the kinase TBK1 (which activates the transcription of type I interferons (IFNs)) phosphorylates Serine 177 of OPTN, enhancing the affinity of LC3 for the binding site of OPTN and, as a consequence, the removal of bacteria. In addition, the researchers showed that mutants of OPTN and OPTN silencing or TBK1 defects lead to intracellular proliferation of $S$. typhimurium (42). Sugars such as $\beta$-galactoside are other host molecules that are also involved in the interaction of bacteria with the autophagy receptors. Under normal conditions, $\beta$-galactoside is located at the luminal surface of the endosome, and when damage occurs in the SCV, this sugar molecule is exposed to the cytosol. This $\beta$-galactoside is then recognized by its cytosolic receptor galectin 8 , which binds to NDP52 and recruits LC3 to the damaged SCV. It is noteworthy that the recruitment of NDP52 to the bacteria is through NDP52 binding to galectin 8, and not to ubiquitin (59). Therefore, ubiquitin signals and sugar contribute to the xenophagy of bacteria in damaged vacuoles. The existence of three adapters (p62, OPTN, and NDP52) ensures the elimination of bacteria present into the host cell cytosol, although the process of pathway activation is not clear at this time (51).

\subsection{Mycobacterium tuberculosis}

In M. tuberculosis infection, autophagy seems to be a mechanism contributing to this bacterium's elimination. One of the main features of the pathogenesis of tuberculosis is the ability of $M$. tuberculosis to infect and survive in alveolar macrophages. Intracellular bacilli are able to arrest phagosome maturation and phagolysosomal fusion (60), inhibiting bactericidal activity and the processing and presentation of mycobacterial antigens (61). Numerous bacterial lipids and proteins have been implicated in the arrest of the phagosome and are involved in the modulation of cytokine secretion $(62,63)$. Infection by $M$. tuberculosis induces granuloma formation, and within this structure, MTB can be maintained in a dormant state for a long time (latency). Latency is the state in which $M$. tuberculosis persists asymptomatically in billions of people (64). Most infected individuals remain asymptomatic and do not get sick. In the latent state, a large number of immune mediators are produced, and particularly IFN- $\gamma$, TNF- $\alpha$, and IL12 (65), and different $\mathrm{T}$ cells are activated, including CD4+, CD8+, T $\gamma \delta$, NKT, T reg and Th17 cells (6668 ). This immunological control can be damaged with aging, nutritional changes, environmental changes, HIV infection, or immunosuppressive treatments (69). Several research groups have shown that autophagy has an important role in the control of tuberculosis. In 2004, Gutierrez and colleagues showed that autophagy induced by starvation, pharmacologically induced by rapamycin, or immunologically induced by IFN- $\gamma$ had the ability to efficiently inhibit the intracellular replication of tuberculous bacilli in macrophages (7). These results were corroborated in different contexts by several groups, which also confirmed that $M$. tuberculosis can be eliminated by stimulating the autophagic pathway. Two different research groups showed that stimulating MTB-infected cells with different TLR agonists decreased the survival of $M$. tuberculosis $(10,13)$. Moreover, Alonso and colleagues showed that autolysosomes containing ubiquitinated fragments could act as mycobactericidal peptides (70). Biswas and colleagues reported that autophagy induced by ATP/P2X7 leads to the elimination of mycobacteria (9). As mentioned above, IFN- $\gamma$ has a valuable role in the response to $M$. tuberculosis because this cytokine induces a protective response. IFN- $\gamma$ may also induce xenophagy and, in conjunction with the GTPase LRG47 in mice (IRGM in humans), contribute to controlling mycobacterial infection in macrophages treated with IFN- $\gamma$ compared with mice deficient in LRG-47, which quickly succumb to bacterial infection (71). It is also known that vitamin $\mathrm{D}$ is important in mycobacterial infection, that low levels of vitamin D in the serum are associated with reactivation of disease and that peripheral blood cells treated with vitamin $\mathrm{D}$ ex vivo can enhance immunity (72,73). In 2009, Yuk and colleagues showed that the active form of vitamin $\mathrm{D}$, or 1, 25-dihydroxyvitamin D (1,25D3), induced autophagy in human monocytes via cathelicidin, which activated transcription of the autophagy-related genes BECN1 and Atg5. 1,25D3 also induced the colocalization of mycobacterial phagosomes with autophagosomes in human macrophages in a cathelicidin-dependent manner (74).

A recent study showed that approximately $30 \%$ of $M$. tuberculosis-containing phagosomes were selectively labeled by LC3 and ATG12 at $4 \mathrm{~h}$ postinfection. Evidence indicates that M. tuberculosis causes damage to the phagosomal membrane via ESAT6 and ESX-1 type VII secretion systems. Autophagy is induced following the phagosomal membrane damage, which allows selective autophagy adapters such as p62, NDP52 and LC3 to access the mycobacteriacontaining phagosome. In the same study, it was 
shown that $M$. tuberculosis DNA may function as a signal to activate selective autophagy, possibly after activation of TBK1 and STING, molecules required for ubiquitin-mediated autophagy (75). In an in vivo model consisting of Atg $5 \mathrm{fl} / \mathrm{fl}$ LysM-Cre transgenic mice (deficient in autophagy), it was demonstrated that these mice are highly susceptible to mycobacterial infection, highlighting autophagy as a determinant of host resistance to M. tuberculosis infection in vivo (76).

\subsection{Legionella pneumophila}

Certain bacteria inhibit autophagy by interfering directly with components of autophagy. An example is Legionella pneumophila, a bacterium that induces autophagy type IV system secretion (T4SS, also known as the secretion system Dot/Icm)-dependent manner. Moreover, this pathogen continuously replicates within acidic lysosomal vacuoles in macrophages and inhibits immediate delivery to the lysosomes, thus persisting in immature autophagosomal vacuoles (77). Legionella is internalized into a phagosome enveloped by endoplasmic reticulum structures (a mechanism that favors bacterial replication), to which components of autophagy such as ATG7 and LC3 are recruited sequentially to be eventually eliminated by lysosomes. However, it has recently been shown that L. pneumophila can evade autophagy during infection of human embryonic kidney 293 cells through the secretion of T4SS and the effector protein RavZ. RavZ is a cysteine protease with ATG4-like function whose direct target is the amide bond between tyrosine and glycine at the carboxyl terminus of LC3, which is covalently bonded to phosphatidylethanolamine (PE) when autophagy is induced. Then, RavZ irreversibly separates LC3 of PE and the autophagosome formation is inhibited (78). This is the first evidence of an effector protein can mimic the function of the components of autophagy in a host to modify a protein critical for autophagy.

\subsection{Shigella flexneri}

S. flexneri is another example of a bacterium that interferes with components of autophagy. S. flexneri is a gram-negative pathogen that has the ability to escape from the endosome and into the cytosol. In the cytosol, Shigella uses the surface protein IcsA to recruit N-WASP and the Arp2/3 complex to form actin tails for motility (79). Autophagy is activated by the recognition of IcsA by ATG5, mediated by tectonic beta-propeller repeatcontaining protein 1 (TECPR1), which binds to ATG5 and promotes autophagosome-lysosome fusion $(80,81)$. Shigella can manipulate the autophagic pathway by secreting factors via T3SS. Among these factors, IcsB and IcsA (VirG) are essential molecules that play a crucial role in bacterial escape from autophagy. IcsB competitively binds to IcsA, reducing binding of
ATG5 and recruitment of TECPR1. This disables the recognition of Shigella by the autophagic machinery $(81,82)$. In studies with mutant IcsB $(-/-)$, it has been demonstrated that LC3 is efficiently recruited and that intracellular bacterial replication decreases with respect to the wild-type strain (82). TECPR1 has an important role in autophagy; TECPR1-deficient mouse embryonic fibroblasts were defective for selective autophagy and supported increased intracellular multiplication of Shigella. Furthermore, depolarized mitochondria and misfolded protein aggregates accumulated in the TECPR1-knockout cells. A TECPR1-dependent pathway is important in targeting bacterial pathogens for selective autophagy (81). Furthermore, it is known that the Shiga toxin induces autophagy in THP-1 cells and human macrophages and promotes death of kidney epithelial cells through a mechanism dependent on autophagy. In toxin-sensitive cells, toxins are translocated to the endoplasmic reticulum, and calpain, caspase- 3 and caspase- 8 are activated, resulting in the cleavage of ATG5 and beclin-1 (83). Moreover, it is known that Shigella encodes another effector protein, VirA. VirA plays an important role in the evasion of autophagy, functioning as an inhibitor of GTPase -Rab1 (a small GTPase that has an important role in the formation of autophagosomes), so the suppression of autophagy contributes to the intracellular survival of Shigella (84). To restrict bacterial motility and escape autophagy, the septins (in contrast to actin and microtubules, septins assemble into nonpolar filaments, and they associate with cellular membranes, actin filaments and microtubules), regarded as the fourth component of the cytoskeleton $(85,86)$, are recruited to IcsA-induced actin polymerization sites to form septin cage-like structures with ubiquitinated proteins and autophagy receptors (p62, NBR1 and NDP52) $(87,88)$. Shigella provides an example of a bacterium that can be a target for autophagy through an ubiquitin-independent (recognized by ATG5-TECPR1) or ubiquitin-dependent (recognized by autophagy receptors) mechanism (89).

\subsection{Listeria monocytogenes}

L. monocytogenes is another example of a pathogen that can evade recognition by the autophagic machinery. In mouse macrophages, L. monocytogenes is internalized by phagocytosis. Inside the phagosome, the bacterium forms pores by secreting listeriolysin O (LLO), and it replicates in the cytosol after escaping from the phagosome (90). Phospholipase C (PLC) of $L$. monocytogenes, in the form of PI-PLC and PC-PLC works synergistically with LLO to lyse phagosomes and to promote invasion of the bacterium into the cytosol, and PLC also inhibits autophagy $(91,92)$. During the initial phase of infection by Listeria (approximately 2 $\mathrm{h}$ post-infection), autophagy plays a crucial role in host immune defense. L. monocytogenes replicates efficiently 
in mouse embryonic fibroblasts deficient in ATG5 compared with the wild type, suggesting a vital role for autophagy in inhibiting intracellular replication $(91,92)$. In 2008, Zhao and colleagues showed that the ATG5 protein is essential for immunity to Listeria infection in vivo (93). In the cytosol, Listeria uses its surfaceexpressed ActA protein to directly recruit the Arp2/3 complex and to form actin tails for motility, conferring the ability to spread to other cells (94). At the same time, ActA prevents ubiquitination and the recruitment of autophagy receptors (p62 and NDP52) to Listeria $(89,95)$. This mechanism has been proposed to help the bacteria to escape autophagy $(91,96)$. ActA-deficient L. monocytogenes is not able to recruit the Arp $2 / 3$ complex; instead, ActA binds p62 and LC3, and finally, the bacteria are removed by xenophagy (95). Another protein that acts similarly to Act A is InIK (97). ActAdeficient L. monocytogenes increases the expression of InIK, allowing the bacteria to survive compared with the wild type. The InIK protein has a redundant role in ActA-deficient L. monocytogenes, replacing ActA, which enables the bacteria to escape autophagy. Together, these studies indicate that L. monocytogenes has dual mechanisms to regulate autophagy. Although activation of autophagy in an LLO-dependent manner is an important mechanism in defense against infection, L. monocytogenes has developed diverse mechanisms of evasion involving several virulence factors, such as PLCs, ActA and InIK.

\subsection{Coxiella burnetii}

In contrast to bacteria that try to evade autophagy, certain bacteria exploit autophagy and promote the formation of autophagic vacuoles in which to multiply. Coxiella burnetii, the etiologic agent of $\mathrm{Q}$ fever, is an obligate intracellular bacterium. This microorganism has efficiently adapted to survive and replicate in the harsh environment of large, acidified phagolysosomelike vacuoles, although the mechanism of its resistance to acid hydrolases is largely unknown. The metabolism of $C$. burnetii is activated, at least in part, by the low $\mathrm{pH}$ found within the phagolysosome (98). Once internalized, Coxiella begins to accumulate along with LC3 in vacuoles called Coxiella-containing vacuoles (CCVs) $(98,99)$. For LC3 to remain in the CCV, bacterial protein synthesis is required; Romano and colleagues showed that treatment with chloramphenicol prevents the association of LC3 (100). Coxiella requires the T4SS to create specialized lysosome-vacuoles to allow bacterial replication $(101,102)$. Furthermore, it is known that Coxiella delays endosome-lysosome fusion, enabling the bacterium to replicate. When autophagy is induced by starvation conditions or treatment with rapamycin, surprisingly, the percentage of infected cells and the size and development of the CCV increase, as does $C$. burnetii replication, indicating that autophagy promotes these phenomena $(100,103)$. Coxiella uses the autophagic process to its advantage and survives in cells.

\subsection{Porphyromonas gingivalis}

$P$. gingivalis is a periodontal pathogen that is also associated with cardiovascular disease. $P$. gingivalis activates autophagy after being internalized. Although this bacterium is sequestered in autophagosomes, it evades the formation of autolysosomes. In human coronary artery endothelial cells (HCAECs), numerous intracellular $P$. gingivalis bacteria were located in multimembranous vacuoles resembling autophagosomes. Vacuoles containing $P$. gingivalis colocalize with Rab5 and HsGsa7p (ATG7) early after internalization. At later times, $P$. gingivalis colocalizes with BiP (Binding immunoglobulin protein) and then progresses to a vacuole that contains $\mathrm{BiP}$ and lysosomal glycoprotein 120. Late endosomal markers and lysosomal cathepsin L do not colocalize with $P$. gingivalis. The intracellular survival of $P$. gingivalis decreases with pretreatment with the autophagy inhibitors 3-methyladenine and wortmannin, resulting in a marked decrease in bacterial survival with respect to untreated cells. These results suggest that $P$. gingivalis requires the induction of autophagy to avoid lysosomal degradation and remain in cells $(104,105)$.

\section{Conclusions}

In the xenophagy, the pathogens elimination is mediated by lysosomal pathway. Some bacterial pathogens, such as $C$. burnetti and $P$. gingivalis inhibit the autolysosome formation, take advantage of autophagy and use the autophagy machinery to establish a replicative niche in autophagosomes. In contrast, $M$. tuberculosis is eliminated efficiently when autophagy is induced. However, pathogens have developed several mechanisms to avoid autophagy (Figure 2). Some intracellular pathogens have the ability to escape from endosome to cytosol. In this context, the autophagy can be induced by different signal: $i$ ) the bacterial cytosolic location, $i i$ ) the phagosomal membrane damage, or iii) the bacterial protein secretion. In the cytosol, the pathogens as $S$. typhimurium can be a target of autophagy through ubiquitin-dependent mechanism mediated by p62, NDP52 and OPTN or ubiquitin independent process through ATG5-TECPR1 as described to S. flexneri. The induction of autophagy results in the clearance of some pathogens, but in other cases, the pathogens evade the autophagy through virulence factors production, which prevent the ubiquitination or degrade key proteins of autophagy. Thus, autophagy plays an important role in the immune response of the infected cells. Like a coin, autophagy could be showing two faces; $i$ ) an efficient 
mechanism to kill and eliminate intracellular pathogens, and $i$ ) a modulated pathway by pathogens to survive and replicate.

Based on these studies, it is evident that autophagy can be an effective immune response for the elimination of intracellular bacteria. Recent studies suggest that induction of autophagy could function as a treatment for certain infectious diseases and could be an effective strategy in vitro and in vivo $(106,107)$. However, only few pathogenic bacteria have been studied in detail, and it is currently unclear whether this can be widely applied to a variety of different bacteria. It is known that a variety of different stimuli can activate xenophagy, such as treatment with IFN- $\gamma$ and stimulation of TLRs $(10,13,108)$. Considering the variety of mechanisms that allow certain pathogens to prevent autophagy, it is necessary to better understand these mechanisms to determine an effective strategy for manipulating autophagy to counteract bacterial invasion in different diseases. In summary, there are currently more questions than answers in the field of autophagy, so more research is needed to clarify the role of autophagy in eliminating pathogens.

\section{Acknowledgements}

NSCJ and KLP would like to acknowledge CONACYT and BEIFI for their fellowships. BEGP and JLH received fellowships from COFAA, EDI and SNI. The authors acknowledge the financial support from "Fondo Sectorial de Investigación para la Educación" Conacyt 222001.

\section{References}

1. Levine B, Kroemer G. Autophagy in the pathogenesis of disease Cell. 2008; 132:27-42.

2. Mizushima N, Komatsu M. Autophagy: Renovation of cells and tissues. Cell. 2011; 147:728-741.

3. Ravikumar B, Sarkar S, Davies JE, et al. Regulation of mammalian autophagy in physiology and pathophysiology. Physiol Rev. 2010; 90:1383-1435.

4. Levine B, Deretic V. Unveiling the roles of autophagy in innate and adaptive immunity. Nat Rev Immunol. 2007; 7:767-777.

5. English L, Chemali M, Duron J, Rondeau C, Laplante A, Gingras D, Alexander D, Leib D, Norbury C, Lippé R, Desjardins M. Autophagy enhances the presentation of endogenous viral antigens on MHC class I molecules during HSV-1 infection. Nat Immunol. 2009; 10:480-487.

6. Andrade RM, Wessendarp M, Gubbels MJ, Striepen B, Subauste CS. CD40 induces macrophage anti-Toxoplasma gondii activity by triggering autophagy-dependent fusion of pathogen-containing vacuoles and lysosomes. J Clin Invest. 2006; 116:2366-2377.

7. Gutierrez MG, Master SS, Singh SB, Taylor GA, Colombo MI, Deretic V. Autophagy is a defense mechanism inhibiting BCG and Mycobacterium tuberculosis survival in infected macrophages. Cell. 2004; 119:753-766.

8. Ling YM, Shaw MH, Ayala C, Coppens I, Taylor GA,
Ferguson DJ, Yap GS. Vacuolar and plasma membrane stripping and autophagic elimination of Toxoplasma gondii in primed effector macrophages. J Exp Med. 2006; 203:2063-2071.

9. Biswas D, Qureshi OS, Lee WY, Croudace JE, Mura M, Lammas DA. ATP-induced autophagy is associated with rapid killing of intracellular mycobacteria within human monocytes/macrophages. BMC Immunol. 2008; 9:35.

10. Delgado MA, Elmaoued RA, Davis AS, Kyei G, Deretic V. Toll-like receptors control autophagy. EMBO J. 2008; 27:1110-1121

11. Saitoh T, Fujita N, Jang MH, et al. Loss of the autophagy protein Atg16L1 enhances endotoxin-induced IL-1beta production. Nature. 2008; 456:264-268.

12. Sanjuan MA, Dillon CP, Tait SW, Moshiach S, Dorsey F, Connell S, Komatsu M, Tanaka K, Cleveland JL, Withoff $\mathrm{S}$, Green DR. Toll-like receptor signalling in macrophages links the autophagy pathway to phagocytosis. Nature. 2007; 450:1253-1257.

13. Xu Y, Jagannath C, Liu XD, Sharafkhaneh A, Kolodziejska KE, Eissa NT. Toll-like receptor 4 is a sensor for autophagy associated with innate immunity. Immunity. 2007; 27:135-144.

14. Yano T, Mita S, Ohmori H, Oshima Y, Fujimoto Y, Ueda R, Takada H, Goldman WE, Fukase K, Silverman N, Yoshimori T, Kurata S. Autophagic control of listeria through intracellular innate immune recognition in drosophila. Nat Immunol. 2008; 9:908-916.

15. Bernales S, McDonald KL, Walter P. Autophagy counterbalances endoplasmic reticulum expansion during the unfolded protein response. PLoS Biol. 2006; 4:e423.

16. Deretic V, Levine B. Autophagy, immunity, and microbial adaptations. Cell Host Microbe. 2009; 5:527-549.

17. Filimonenko M, Isakson P, Finley KD, Anderson M, Jeong H, Melia TJ, Bartlett BJ, Myers KM, Birkeland HC, Lamark T, Krainc D, Brech A, Stenmark H, Simonsen A, Yamamoto A. The selective macroautophagic degradation of aggregated proteins requires the PI3P-binding protein. Alfy Mol Cell. 2010; 38:265-279.

18. Geisler S, Holmström KM, Skujat D, Fiesel FC, Rothfuss OC, Kahle PJ, Springer W. PINK1/Parkin-mediated mitophagy is dependent on VDAC1 and p62/SQSTM1. Nat Cell Biol. 2010; 12:119-131.

19. Iwata J, Ezaki J, Komatsu M, Yokota S, Ueno T, Tanida I, Chiba T, Tanaka K, Kominami E. Excess peroxisomes are degraded by autophagic machinery in mammals. J Biol Chem. 2006; 281:4035-4041.

20. Singh R, Kaushik S, Wang Y, Xiang Y, Novak I, Komatsu M, Tanaka K, Cuervo AM, Czaja MJ. Autophagy regulates lipid metabolism. Nature. 2009; 458:1131-1135.

21. Behrends C, Fulda S. Receptor proteins in selective autophagy. Intern J Cell Biol. 2012; 2012:1-9.

22. Yen WL, Klionsky D. How to live long and prosper: Autophagy, mitochondria, and aging. Physiology. 2008; 23:248-262.

23. Nakatogawa H, Suzuki K, Kamada Y, Ohsumi Y. Dynamics and diversity in autophagy mechanisms: Lessons from yeast. Nat Rev Mol Cell Biol. 2009; 10:458-467.

24. Settembre C, Di Malta C, Polito VA, Garcia Arencibia M, Vetrini F, Erdin S, Erdin SU, Huynh T, Medina D, Colella P, Sardiello M, Rubinsztein DC, Ballabio A. TFEB links autophagy to lysosomal biogenesis. Science. 2011; 332:1429-1433.

25. Masiero E, Agatea L, Mammucari C, Blaauw B, Loro E, 
Komatsu M, Metzger D, Reggiani C, Schiaffino S, Sandri M. Autophagy is required to maintain muscle mass. Cell Metab. 2009; 10:507-515.

26. Deretic V. Autophagy: An emerging immunological paradigm. J Immunol. 2012; 189:15-20.

27. Bjørkøy G, Lamark T, Brech A, Outzen H, Perander M, Overvatn A, Stenmark H, Johansen T. p62/SQSTM1 forms protein aggregates degraded by autophagy and has a protective effect on huntingtin-induced cell death. J Cell Biol. 2005; 171:603-614.

28. Pankiv S, Clausen TH, Lamark T, Brech A, Bruun JA, Outzen H, Overvatn A, Bjorkoy G, Johansen T. p62/SQSTM1 binds directly to Atg8/LC3 to facilitate degradation of ubiquitinated protein aggregates by autophagy. J Biol Chem. 2007; 282:24131-24145.

29. Kim PK, Hailey DW, Mullen RT, Lippincott-Schwartz J. Ubiquitin signals autophagic degradation of cytosolic proteins and peroxisomes. Proc Natl Acad Sci U S A. 2008; 105:20567-20574.

30. Novak I, Kirkin V, McEwan DG, Zhang J, Wild P, Rozenknop A, Rogov V, Löhr F, Popovic D, Occhipinti A, Reichert AS, Terzic J, Dötsch V, Ney PA, Dikic I. Nix is a selective autophagy receptor for mitochondrial clearance. EMBO Rep. 2010; 11:45-51

31. Jiang S, Wells CD, Roach PJ. Starch-binding domaincontaining protein 1 (Stbd1) and glycogen metabolism: Identification of the Atg8 family interacting motif (AIM) in Stbd1 required for interaction with GABARAPL1. Biochem Biophys Res Commun. 2011; 413:420-425.

32. Grasso D, Ropolo A, Lo Ré A, Boggio V, Molejón MI, Iovanna JL, Gonzalez CD, Urrutia R, Vaccaro MI. Zymophagy, a novel selective autophagy pathway mediated by VMP1-USP9x-p62, prevents pancreatic cell death. J Biol Chem. 2011; 286:8308-8324.

33. Kraft C, Deplazes A, Sohrmann M, Peter M. Mature ribosomes are selectively degraded upon starvation by an autophagy pathway requiring the Ubp3p/Bre 5p ubiquitin protease. Nat Cell Biol. 2008; 10:602-610.

34. Levine, B. Eating oneself and uninvited guests: Autophagy-related pathways in cellular defense. Cell. 2005; 120:159-162.

35. Noda NN, Kumeta H, Nakatogawa H, Satoo K, Adachi W, Ishii J, Fujioka Y, Ohsumi Y, Inagaki F. Structural basis of target recognition by Atg8/LC3 during selective autophagy. Genes to Cells. 2008; 13:1211-1218.

36. Johansen T, Lamark T. Selective autophagy mediated by autophagic adapter proteins. Autophagy. 2011; 7:279-296.

37. Komatsu M, Waguri S, Koike M, et al. Homeostatic levels of p62 control cytoplasmic inclusion body formation in autophagy-deficient mice. Cell. 2007; 131:1149-1163.

38. Moscat J, Diaz-Meco MT, Wooten MW. Signal integration and diversification through the p62 scaffold protein. Trends Biochem Sci. 2007; 32:95-100.

39. Kuusisto E, Salminen A, Alafuzoff I. Ubiquitin-binding protein p62 is present in neuronal and glial inclusions in human tauopathies and synucleinopathies. Neuroreport. 2001; 12:2085-2090.

40. Zatloukal K, Stumptner C, Fuchsbichler A, Heid H, Schnoelzer M, Kenner L, Kleinert R, Prinz M, Aguzzi A, Denk H. p62 Is a common component of cytoplasmic inclusions in protein aggregation diseases. Am J Pathol. 2002; 160:255-263.

41. Thurston TL Ryzhakov G, Bloor S, Von Muhlinen N, Randow F. The TBK1 adaptor and autophagy receptor NDP52 restricts the proliferation of ubiquitin-coated bacteria. Nat Immunol. 2009; 10:1215-1221

42. Wild P, Farhan H, McEwan DG, Wagner S, Rogov VV, Brady NR, Richter B, Korac J, Waidmann O, Choudhary C, Dötsch V, Bumann D, Dikic I. Phosphorylation of the autophagy receptor optineurin restricts Salmonella growth. Science. 2011; 333:228-233.

43. Huang J, Canadien V, Lam GY, Steinberg BE, Dinauer MC, Magalhaes MA, Glogauer M, Grinstein S, Brumell JH. Activation of antibacterial autophagy by NADPH oxidases. Proc Natl Acad Sci U S A. 2009; 106:62266231.

44. Florey O, Kim SE, Sandoval CP, Haynes, CM, Overholtzer M. Autophagy machinery mediates macroendocytic processing and entotic cell death by targeting single membranes. Nat Cell Biol. 2011; 13:13351343.

45. Shaid S, Brandts $\mathrm{CH}$, Serve H, Dikic I. Ubiquitination and selective autophagy. Cell Death Differ. 2013; 20:21-30.

46. Rikihisa Y.Glycogen autophagosomes in polymorphonuclear leukocytes induced by rickettsiae. Anat Rec. 1984; 208:319-327.

47. Nakagawa I, Amano A, Mizushima N, Yamamoto A, Yamaguchi H, Kamimoto T, Nara A, Funao J, Nakata M, Tsuda K, Hamada S, Yoshimori T. Autophagy defends cells against invading group A Streptococcus. Science. 2004; 306:1037-1040.

48. Sakurai A, Maruyama F, Funao J, Nozawa T, Aikawa C, Okahashi N, Shintani S, Hamada S, Ooshima T, Nakagawa I. Specific behavior of intracellular Streptococcus pyogenes that has undergone autophagic degradation is associated with bacterial streptolysin $\mathrm{O}$ and host small G proteins Rab5 and Rab7. J Biol Chem. 2010; 285:22666-22675

49. Joubert PE, Meiffren G, Grégoire IP, Pontini G, Richetta C, Flacher M, Azocar O, Vidalain PO, Vidal M, Lotteau V, Codogno P, Rabourdin-Combe C, Faure, M. Autophagy induction by the pathogen receptor CD46. Cell Host Microbe. 2009; 6:354-366.

50. Nozawa T, Aikawa C, Goda A, Maruyama F, Hamada S, Nakagawa I. The small GTPases Rab9A and Rab23 function at distinct steps in autophagy during Group A Streptococcus infection. Cell Microbiol. 2012; 14:11491165.

51. Huang J, Brumell JH. Bacteria-autophagy interplay: A battle for survival. Nat Rev Microbiol. 2014; 12:101-114.

52. O'Seaghdha M, Wessels MR. Streptolysin O and its co toxin NAD-glycohydrolase protect group A Streptococcus from xenophagic killing. PLoS Pathog. 2013; 9:e1003394.

53. Bakowski MA, Braun V, Brumell JH. Salmonellacontaining vacuoles: Directing traffic and nesting to grow. Traffic. 2008; 9:2022-2031

54. Schroeder N, Mota LJ, Méresse S. Salmonella-induced tubular networks. Trends Microbiol. 2011; 19:268-277.

55. Perrin AJ, Jiang X, Birmingham CL, So NS, Brumell JH. Recognition of bacteria in the cytosol of mammalian cells by the ubiquitin system. Curr Biol. 2004; 14:806-811.

56. Birmingham CL, Smith AC, Bakowski MA, Yoshimori T, Brumell JH. Autophagy controls Salmonella infection in response to damage to the Salmonella-containing vacuole. J Biol Chem. 2006; 281:11374-11383.

57. Zheng YT, Shahnazari S, Brech A, Lamark T, Johansen $\mathrm{T}$, Brumell JH. The adaptor protein p62/SQSTM1 targets invading bacteria to the autophagy pathway. J Immunol. 2009; 183:5909-5916.

58. Thurston TL, Wandel MP, Von Muhlinen N, Foeglein 
A, Randow F. Galectin 8 targets damaged vesicles for autophagy to defend cells against bacterial invasion. Nature. 2012; 482:414-418.

59. Barnett TC, Liebl D, Seymour LM, Gillen CM, Lim JY, Larock CN, Davies MR, Schulz BL, Nizet V, Teasdale RD, Walker MJ. The globally disseminated M1T1 clone of group A Streptococcus evades autophagy for intracellular replication. Cell Host Microbe. 2013; 14:675-82.

60. Armstrong JA, Hart PD. Phagosome-lysosome interactions in cultured macrophages infected with virulent tubercle bacilli. Reversal of the usual nonfusion pattern and observations of bacterial survival. J Exp Med. $1975 ; 142: 1-16$.

61. Ramachandra L, Smialek JL, Shank SS, Convery M, Boom WH, Harding CV. Phagosomal processing of Mycobacterium tuberculosis antigen $85 \mathrm{~B}$ is modulated independently of mycobacterial viability and phagosome maturation. Infect Immun. 2005; 73:1097-1105.

62. Philips JA. Mycobacterial manipulation of vacuolar sorting. Cell Microbiol. 2008; 10:2408-2415.

63. Steinhäuser C, Heigl U, Tchikov V, et al. Lipid-labeling facilitates a novel magnetic isolation procedure to characterize pathogen-containing phagosomes. Traffic. 2013; 14:321-336.

64. Manabe YC, Bishai WR. Latent Mycobacterium tuberculosis-persistence, patience, and winning by waiting. Nat Med. 2000; 6:1327-1329.

65. Flynn JL, Chan J. Immunology of tuberculosis. Annu Rev Immunol. 2001; 19:93-129.

66. Behar S, Boom W. Unconventional T cells. In: Handbook of tuberculosis: Immunology and cell biology (Kaufmann $\mathrm{S}$, Britton W, eds.). Wiley-VCH, Weinheim, Germany, 2008; pp. 157-183.

67. Lewinsohn DM, Briden AL, Reed SG, Grabstein KH, Alderson MR. Mycobacterium tuberculosis reactive CD8+ $\mathrm{T}$ lymphocytes: The relative contribution of classical versus non-classical HLA restriction. J Immunol. 2000; 165:925-930.

68. Ottenhoff H, Lewinsohn D, Lewinsohn D. Human CD4 and CD8 cell responses to Mycobacterium tuberculosis: Antigen specificity, function, implications and applications. In: Handbook of tuberculosis: Immunology and cell biology (Kaufmann S, Britton D, eds.). WileyVCH, Weinheim, Germany, 2008; pp. 119-155.

69. Saunders BM, Britton WJ. Life and death in the granuloma: Immunopathology of tuberculosis. Immunol Cell Biol. 2007; 85:103-111.

70. Alonso S, Pethe K, Russell DG, Purdy GE. Lysosomal killing of Mycobacterium mediated by ubiquitin-derived peptides is enhanced by autophagy. Proc Natl Acad Sci U S A. 2007; 104:6031-6036.

71. MacMicking JD, Taylor GA, McKinney JD. Immune control of tuberculosis by IFN-gamma-inducible LRG-47. Science. 2003; 302:654-659.

72. Martineau AR, Wilkinson RJ, Wilkinson KA, Newton SM, Kampmann B, Hall BM, Packe GE, Davidson RN, Eldridge SM, Maunsell ZJ, Rainbow SJ, Berry JL, Griffiths CJ. A single dose of vitamin D enhances immunity to mycobacteria. Am J Respir Crit Care Med. 2007; 176:208-213.

73. Nnoaham KE, Clarke A. Low serum vitamin D levels and tuberculosis: A systematic review and meta-analysis. Int $\mathrm{J}$ Epidemiol. 2008; 37:113-119.

74. Yuk JM, Shin DM, Lee HM, Yang CS, Jin HS, Kim KK, Lee ZW, Lee SH, Kim JM, Jo EK. Vitamin D3 induces autophagy in human monocytes/macrophages via cathelicidin. Cell Host Microbe. 2009; 6:231-243.

75. Watson RO, Manzanillo PS, Cox JS. Extracellular $M$. tuberculosis DNA targets bacteria for autophagy by activating the host DNA-sensing pathway. Cell. 2012; 150:803-815.

76. Castillo EF, Dekonenko A, Arko-Mensah J, Mandell MA, Dupont N, Jiang S, Delgado-Vargas M, Timmins GS, Bhattacharya D, Yang H, Hutt J, Lyons CR, Dobos KM, Deretic V. Autophagy protects against active tuberculosis by suppressing bacterial burden and inflammation. Proc Natl Acad Sci U S A. 2012; 109:E3168-3176.

77. Amer AO, Swanson MS. Autophagy is an immediate macrophage response to Legionella pneumophila. Cell Microbiol. 2005; 7:765-778.

78. Choy A, Dancourt J, Mugo B, O'Connor TJ, Isberg RR, Melia TJ, Roy CR. The Legionella effector RavZ inhibits host autophagy through irreversible Atg8 deconjugation. Science. 2012; 338:1072-1076.

79. Haglund CM, Welch, MD. Pathogens and polymers: Microbe-host interactions illuminate the cytoskeleton. J Cell Biol. 2011; 195:7-17.

80. Chen D, Fan W, Lu Y, Ding X, Chen S, Zhong Q. A mammalian autophagosome maturation mechanism mediated by TECPR1 and the Atg12-Atg5 conjugate. Mol Cell. 2012; 45:629-641.

81. Ogawa M, Yoshikawa Y, Kobayashi T, et al. A Tecpr1dependent selective autophagy pathway targets bacterial pathogens. Cell Host Microbe. 2011; 9:376-389.

82. Ogawa M, Yoshimori T, Suzuki T, Sagara H, Mizushima N, Sasakawa C. Escape of intracellular Shigella from autophagy. Science. 2005; 307:727-731.

83. Lee MS, Cherla RP, Jenson MH, Leyva-Illades D, Martinez-Moczygemba M, Tesh VL. Shiga toxins induce autophagy leading to differential signalling pathways in toxin-sensitive and toxin-resistant human cells. Cell Microbiol. 2011; 13:1479-1496.

84. Dong N, Zhu Y, Lu Q, Hu L, Zheng Y, Shao F. Structurally distinct bacterial TBC-like GAPs link Arf GTPase to Rab1 inactivation to counteract host defenses. Cell. 2012; 150:1029-1041.

85. Kinoshita M. Diversity of septin scaffolds. Curr Opin Cell Biol. 2006; 18:54-60.

86. Sirajuddin, M, Farkasovsky M, Hauer F, Kühlmann D, Macara IG, Weyand M, Stark H, Wittinghofer A. Structural insight into filament formation by mammalian septins. Nature. 2007; 449:311-315.

87. Mostowy S, Bonazzi M, Hamon MA, Tham TN, Mallet A, Lelek M, Gouin E, Demangel C, Brosch R, Zimmer C, Sartori A, Kinoshita M, Lecuit M, Cossart P. Entrapment of intracytosolic bacteria by septin cage-like structures. Cell Host Microbe. 2010; 8:433-444.

88. Mostowy S, Sancho-Shimizu V, Hamon MA, Simeone, R, Brosch R, Johansen T, Cossart P. p62 and NDP52 proteins target intracytosolic Shigella and Listeria to different autophagy pathways. J Biol Chem. 2011; 286:2698726995.

89. Mostowy S. Autophagy and bacterial clearance: A not so clear picture. Cell Microbiol. 2013; 15:395-402.

90. Dussurget O, Pizarro-Cerda J, Cossart P. Molecular determinants of Listeria monocytogenes virulence. Annu Rev Microbiol. 2004; 58:587-610.

91. Birmingham CL, Canadien V, Gouin E, Troy EB, Yoshimori T, Cossart P, Higgins DE, Brumell JH. Listeria monocytogenes evades killing by autophagy during 
colonization of host cells. Autophagy. 2007; 3:442-451.

92. Py BF, Lipinski MM, Yuan J. Autophagy limits Listeria monocytogenes intracellular growth in the early phase of primary infection. Autophagy. 2007; 3:117-125.

93. Zhao Z, Fux B, Goodwin M, et al. Autophagosomeindependent essential function for the autophagy protein Atg5 in cellular immunity to intracellular pathogens. Cell Host Microbe. 2008; 4:458-469.

94. Gouin E, Welch MD, Cossart P. Actin-based motility of intracellular pathogens. Curr Opin Microbiol. 2005; 8:3545.

95. Yoshikawa Y, Ogawa M, Hain T, Yoshida M, Fukumatsu M, Kim M, Mimuro H, Nakagawa I, Yanagawa T, Ishii T, Kakizuka A, Sztul E, Chakraborty T, Sasakawa C. Listeria monocytogenes ActA mediated escape from autophagic recognition. Nat Cell Biol. 2009; 11:1233-1240.

96. Lam GY, Cemma M, Muise AM, Higgins DE, Brumell $\mathrm{JH}$. Host and bacterial factors that regulate LC3 recruitment to Listeria monocytogenes during the early stages of macrophage infection. Autophagy. 2013; 9:985995.

97. Dortet L, Mostowy S, Samba-Louaka A, Gouin E, Nahori MA, Wiemer EA, Dussurget O, Cossart P. Recruitment of the major vault protein by InlK: A Listeria monocytogenes strategy to avoid autophagy. PLoS Pathog. 2011; 7:e1002168.

98. Heinzen RA, Scidmore MA, Rockey DD, Hackstadt T. Differential interaction with endocytic and exocytic pathways distinguish parasitophorous vacuoles of Coxiella burnetii and Chlamydia trachomatis. Infect Immun. 1996; 64:796-809.

99. Berón W, Gutierrez MG, Rabinovitch M, Colombo MI. Coxiella burnetii localizes in a Rab7-labeled compartment with autophagic characteristics. Infect Immun. 2002; 70:5816-5821.

100. Romano PS, Gutiérrez MG, Berón W, Rabinovitch M, Colombo MI. The autophagic pathway is actively modulated by phase II Coxiella burnetii to efficiently replicate in the host cell. Cell Microbiol. 2007; 9:891-909.
101. Beare PA, Gilk SD, Larson, CL, Hill J, Stead CM, Omsland A, Cockrell DC, Howe D, Voth DE, Heinzen RA. Dot/Icm type IVB secretion system requirements for Coxiella burnetii growth in human macrophages. MBio. 2011; 2:e00175-11.

102. Carey KL, Newton HJ, Lührmann A, Roy CR. The Coxiella burnetii Dot/Icm system delivers a unique repertoire of type IV effectors into host cells and is required for intracellular replication. PLoS Pathog. 2011; $7: \mathrm{e} 1002056$

103. Gutierrez MG, Vázquez CL, Munafó DB, Zoppino FC, Berón W, Rabinovitch M, Colombo MI. Autophagy induction favours the generation and maturation of the Coxiella-replicative vacuoles. Cell Microbiol. 2005; 7:981-993.

104. Dorn BR, Dunn WA Jr, Progulske-Fox A. Invasion of human coronary artery cells by periodontal pathogens. Infect Immun. 1999; 67:5792-5798.

105. Dorn BR, Dunn WA Jr, Progulske-Fox A, Dortet L, Mostowy S, Samba-Louaka A, Gouin E, Nahori MA, Wiemer EA, Dussurget O, Cossart P. Porphyromonas gingivalis traffics to autophagosomes in human coronary artery endothelial cells. Infect Immun. 2001; 69:569856708

106. Campbell GR, Spector SA. Autophagy induction by vitamin D inhibits both Mycobacterium tuberculosis and human immunodeficiency virus type 1. Autophagy. 2012; 8:1523-1525.

107. Shoji-Kawata S, Sumpter R, Leveno M, et al. Identification of a candidate therapeutic autophagyinducing peptide. Nature. 2013; 494:201-206.

108. Deretic V, Delgado M, Vergne I, Master S, De Haro S, Ponpuak M, Singh S. Autophagy in immunity against Mycobacterium tuberculosis: A model system to dissect immunological roles of autophagy. Curr Top Microbiol Immunol. 2009; 335:169-188.

(Received March 24, 2015; Revised May 15, 2015; Rerevised June 10, 2015; Accepted June 18, 2015) 